OPEN ACCESS

Edited by:

Miriam Schmidts,

Radboud University Nijmegen,

Netherlands

Reviewed by:

Ruxandra Bachmann-Gagescu, Universität Zürich, Switzerland

Rachel Lennon,

University of Manchester,

United Kingdom

Rebecca Ann Wingert,

University of Notre Dame,

United States

*Correspondence:

Jens H. Westhoff

jens.westhoff@med.uni-heidelberg.de

Specialty section:

This article was submitted to

Pediatric Nephrology

a section of the journal

Frontiers in Pediatrics

Received: 15 February 2018

Accepted: 04 June 2018

Published: 28 June 2018

Citation:

Gehrig J, Pandey G and Westhoff JH

(2018) Zebrafish as a Model for Drug

Screening in Genetic Kidney Diseases.

Front. Pediatr. 6:183

doi: 10.3389/fped.2018.00183

\section{Zebrafish as a Model for Drug Screening in Genetic Kidney Diseases}

\author{
Jochen Gehrig ${ }^{1}$, Gunjan Pandey ${ }^{1,2}$ and Jens H. Westhoff ${ }^{2 *}$ \\ ${ }^{1}$ Acquifer is a Division of Ditabis, Digital Biomedical Imaging Systems AG, Pforzheim, Germany, ${ }^{2}$ Department of Pediatrics I, \\ University Children's Hospital Heidelberg, Heidelberg, Germany
}

Genetic disorders account for a wide range of renal diseases emerging during childhood and adolescence. Due to the utilization of modern biochemical and biomedical techniques, the number of identified disease-associated genes is increasing rapidly. Modeling of congenital human disease in animals is key to our understanding of the biological mechanism underlying pathological processes and thus developing novel potential treatment options. The zebrafish (Danio rerio) has been established as a versatile small vertebrate organism that is widely used for studying human inherited diseases. Genetic accessibility in combination with elegant experimental methods in zebrafish permit modeling of human genetic diseases and dissecting the perturbation of underlying cellular networks and physiological processes. Beyond its utility for genetic analysis and pathophysiological and mechanistic studies, zebrafish embryos, and larvae are amenable for phenotypic screening approaches employing high-content and high-throughput experiments using automated microscopy. This includes large-scale chemical screening experiments using genetic models for searching for disease-modulating compounds. Phenotype-based approaches of drug discovery have been successfully performed in diverse zebrafish-based screening applications with various phenotypic readouts. As a result, these can lead to the identification of candidate substances that are further examined in preclinical and clinical trials. In this review, we discuss zebrafish models for inherited kidney disease as well as requirements and considerations for the technical realization of drug screening experiments in zebrafish.

Keywords: zebrafish, drug screening, compound screening, genetic kidney disease, high-throughput, highcontent, automated microscopy

\section{INTRODUCTION}

Modern genetic diagnostics allow the rapid discovery of human disease-associated mutations. Moreover, human genetic disorders can often be mimicked in animal models that can be exploited in large-scale chemical investigations for the search of modifiers of disease-associated phenotypes and potentially therapeutic compounds. The zebrafish (Danio rerio) has become an increasingly accepted vertebrate model organism for biomedical research $(1,2)$.

Despite being a member of the teleost class of fish species, there is great homology in development as well as cell- and organ-specific structural and physiological properties between zebrafish and humans. Furthermore, even with the evolutionary distance, $>80 \%$ of human disease-associated genes have orthologs in the zebrafish genome (3). The embryonic and larval 
characteristics of zebrafish include small size, ex utero development, optical transparency, and rapidity of organogenesis. In combination with the high fecundity of adult zebrafish and a relatively simple and cost-effective animal husbandry, this enables large-scale in vivo investigations. The zebrafish genome has been completely sequenced, thus facilitating genetic and genomic analysis and manipulation $(3,4)$. For instance, reverse genetics allow for precise investigation of associated phenotypes, by e.g., transient gene knockdown using antisense morpholino oligos or by genome-editing technologies like the CRISPR/Cas9 system $(5,6)$.

Due to the simplicity of the pronephros that can be readily studied in embryonic and larval stages, the zebrafish is an applicable experimental model system for the analysis of renal development and disease (7). The pronephros, as the earliest nephric stage, contains two nephrons sharing numerous genetic, structural, and functional aspects with the mammalian nephron (8). Phenotypic changes upon genetic alterations can be easily analyzed within intact live animals (9). Large-scale mutagenesis screens have identified various mutants affecting kidney development allowing the exploration of genetic and molecular mechanisms underlying pronephros development and function $(10,11)$. Moreover, reverse genetics approaches enable researchers to specifically alter orthologous genetic elements potentially associated with human disease. To date, major fields of research where such zebrafish models are being employed include glomerular (i.e., podocytopathies) and cystic renal disorders (i.e., ciliopathies).

Phenotype-based screening for drug discovery applications is increasingly employed in biomedical and pharmaceutical research. In contrast to target-based screening, phenotype-based approaches do not require exact knowledge of the therapeutic target (7). In addition, whole-organism in vivo approaches have the advantage that they can unravel toxic and other side-effects of drugs at a very early stage of the study. Over the last years, due to the versatility and power of the model, the zebrafish has emerged as the main vertebrate model system for high-throughput and high-content chemical screening experiments and large-scale phenotypic scoring $(12,13)$. Clear and scalable readouts for in vivo large-scale experiments can be readily established and a plethora of mutant and transgenic models expressing fluorescent proteins driven by tissue-specific promoters is available. In combination with automation technologies and dedicated sample handling workflows, this has led to various biomedical screening assays in fields such as genetics $(14,15)$, toxicology $(16,17)$, immunology and infection biology $(18,19)$, cardiovascular research $(20,21)$, drug discovery and safety $(12,13,22,23)$, personalized medicine (24), non-coding-genome analysis (25) as well as behavioral analysis $(26,27)$. Notably, several compounds that were identified in the zebrafish model have made it to preclinical and clinical trials, including new substance classes and repurposed drugs (12). For instance, in a chemical genetic screen testing 2.480 compounds, prostaglandin E2 (PGE2) was identified as an evolutionarily conserved regulator of hematopoietic stem cell (HSC) number in zebrafish embryos (28). Based on these results, a chemical derivative of PGE2 (Prohema), has been developed with the aim of improving the efficiency of HSC transplants using umbilical cord blood. Prohema has meanwhile advanced to Phase II clinical trials.

\section{GENETIC KIDNEY DISEASES IN ZEBRAFISH}

Genetic kidney diseases can affect all parts of the kidney and its functions. To date, mutations in more than 150 genes have been identified that cause genetic human kidney diseases such as alterations of kidney development or specific glomerular and tubular diseases (29). Nephrogenesis in vertebrates is an intricate process that includes the successive formation of up to three kidneys depending on the species position in the phylogenetic tree: the pronephros, mesonephros, and metanephros (30). There is an increasing complexity with each successive kidney developing, however the structure and function of the basic renal units, the nephrons, remains largely unvaried across vertebrates (31).

In zebrafish, major vertebrate organ systems form within a few days after fertilization (32). The zebrafish pronephros is functional by $48 \mathrm{hpf}$ (hours post fertilization) accomplishing the functions of blood filtration and osmoregulation $(11,33)$. It consists of two nephrons with a fused glomerulus at the midline (Figure 1A) (24). The tubular system consisting of the pronephric proximal and distal tubule and pronephric duct contains segment-specific conserved structural and physiological properties and spatio-temporal gene-expression patterns that are homologous to the human kidney (Figure 1B) $(8,35,36)$. The zebrafish glomerulus is endowed with podocytes with extended and interdigitating foot processes and fenestrated endothelial cells forming a functional glomerular filtration barrier, analogous to the metanephric glomerulus of higher vertebrates (11).

At present, zebrafish is predominantly used as a genetic model for normal and abnormal kidney development, for hereditary glomerulopathies (i.e., podocytopathies) and for the study of ciliopathy-associated human cystic kidney diseases. These encompass polycystic kidney diseases and diseases of the nephronophthisis/medullary cystic kidney disease complex including more complex ciliopathies such as Joubert Syndrome, Meckel-Gruber Syndrome, and Bardet-Biedl-Syndrome (37). In this review, we focus on glomerulopathies and cystic kidney diseases.

\section{ZEBRAFISH AS A MODEL FOR HUMAN HEREDITARY GLOMERULOPATHIES}

Zebrafish models can recapitulate human genetic glomerulopathies, i.e., a variety of podocytopathies that clinically often manifest by steroid-resistant nephrotic syndrome (SRNS) due to podocyte foot process effacement. SRNS is mostly therapy-resistant and leads to end-stage renal disease (ESRD) within a few years of onset. A growing number of SRNScausing mutations have been identified. For example, mutations in NPHS1, encoding Nephrin, cause congenital nephrotic syndrome of the Finnish type. Morpholino knockdown of $n p h s 1$ in zebrafish results in edema and loss of slit-diaphragms with 


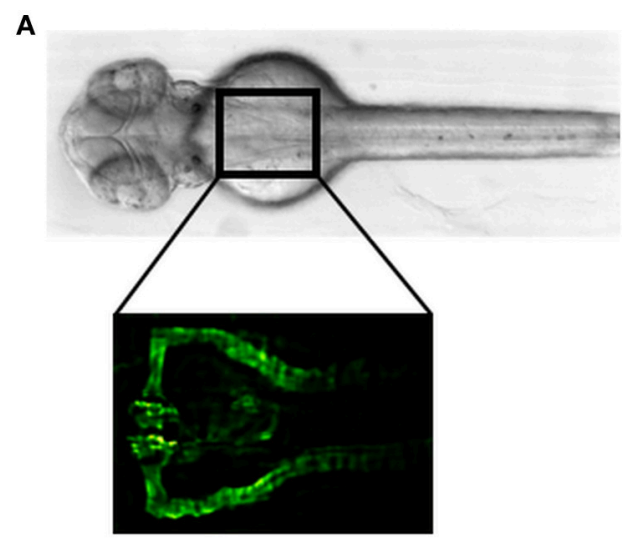

B

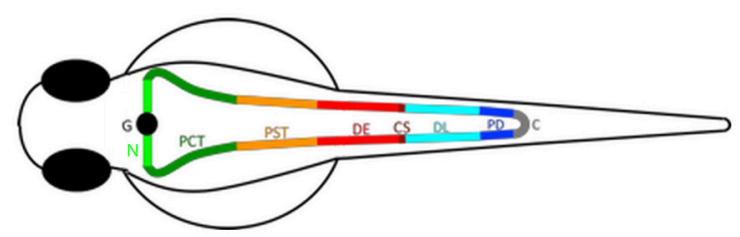

FIGURE 1 | The zebrafish pronephros: anatomical position and segmental organization. (A) Brightfield dorsal view of a 2 day post fertilization (dpf) zebrafish embryo (upper panel). The rectangle in the anterior trunk indicates the location of the proximal pronephric structures with a fused glomerulus at the midline that connects to the segmented pronephric tubules as labeled in the $T g$ (wt1b:egfp) zebrafish line by GFP expression (lower panel). (B) Schematic illustration of a zebrafish pronephros showing segmental organization of each nephron into glomerulus $(\mathrm{G})$, neck (N), proximal convoluted tubule (PCT), proximal straight tubule (PST), distal early (DE), corpuscle of Stannius (CS), distal late (DL), and pronephric duct (PD) that fuse to the cloaca (C). Adapted from Wingert and Davidson (34).

abnormal podocyte foot processes $(38,39)$. Mutations in WT1 (Wilms' tumor gene 1) have been associated with syndromic disorders such as Denys-Drash syndrome and Frasier syndrome, but also with diffuse mesangial sclerosis and early-onset isolated nephrotic syndrome (40). In zebrafish, knockdown of wt1a results in defects in podocyte development leading to glomerular injury and nephrosis (41). Mutations in NPHS2, Podocin, are the most relevant cause of autosomal-recessive SRNS of childhood. Zebrafish nphs 2 morphants display pronephric glomerular hypoplasia with pericardial edema and ultrastructural glomerular damage of the filtration barrier $(38,39)$. Mutations in PLCE1 (Nephrocystin-3, NPHS3) have been identified in patients with SRNS and disease onset in the first year of life with a rapid progression to $\operatorname{ESRD}(42,43)$. Zebrafish plce1 morphants display an impairment of the kidney filtration barrier as measured by tubular uptake of filtered $500 \mathrm{kDa}$ fluorescent dextran, accompanied by edema, and severe disorganization of slit diaphragms (43). Other rare human mutations that were mimicked in zebrafish include $A D C K 4$ (AarF domain containing kinase 4 gene) (44), KANK1 (kidney ankyrin repeat-containing protein 1), KANK2, KANK4 (45), CRB2 (Crumbs homolog 2) (46), NUP107 (Nuclear Pore Complex Subunit 107) (47), and ARHGDIA (48).
Whereas in many studies of genetic glomerulopathies the zebrafish has been used to model human disease-associated phenotypes, disruption of the glomerular filtration barrier can only be visualized by ultrastructural techniques like superresolution or electron microscopy that are not compatible with large-scale chemical screens. Edema formation in zebrafish embryos can indirectly report glomerular barrier impairments; however, despite being easily observed in brightfield microscopy it is not exclusively linked to renal impairment (49). This restricts its value as a phenotypic readout parameter in chemical kidney screens. Functional assessment of glomerular filtration and barrier integrity can be achieved by monitoring the temporal reporter activity after microinjection of fluorescently labeled inulin (50) or dextrans of different molecular weight (51-53) into the vascular system; however, this method is laborious and incompatible with extensive screening experiments. Additionally, a transgenic zebrafish that expresses GFP (green fluorescent protein)-tagged vitamin D-binding protein (VDBP), which acts as a tracer for proteinuria, has been reported (54) and may serve as an attractive alternative for high-content and high-throughput screening (53).

\section{ZEBRAFISH AS A MODEL FOR HUMAN CYSTIC KIDNEY DISEASES}

Cystic diseases of the kidney are frequent monogenic disorders in humans $(55,56)$, with primary cilia dysfunction being the unifying cellular mechanism leading to most if not all cystic kidney diseases (56-58). Mutations in a variety of genes encoding the primary cilia/centrosome complex cause ciliopathies often associated with the development of renal cysts, in both human and zebrafish (59-64). However, it must be noted that cilia in the zebrafish pronephros are motile, whereas human renal cilia are thought to be non-motile $(65,66)$, suggesting a potential contribution of lack of fluid dynamics to cyst formation in the zebrafish model.

Mutations in polycystin-1 and polycystin-2 are responsible for autosomal dominant polycystic kidney disease (ADPKD), the most common human congenital renal disorder (67). In zebrafish, polycystin-2 morpholino knockdown or mutation of orthologous pkd genes induces kidney cysts, hydrocephalus, left/right asymmetry defects, and strong dorsal axis curvature (63, 68, 69). Autosomal recessive polycystic kidney disease (ARPKD) usually manifests perinatally or in childhood. In addition to PKHD1 (polycystic kidney and hepatic disease 1), mutations in DZIP1L (DAZ interacting zinc finger protein 1 like) have recently been associated with $\operatorname{ARPKD}(70,71)$. Other than dzip1l morphants and dzip1l CRISPR mutants, $\mathrm{Lu}$ et al. injected the $d z i p 1 l$ translation-blocking morpholino into $\mathrm{Tg}(w t 1 b: e g f p)$ transgenic embryos expressing GFP under Wilms' tumor suppressor (wt1b) promoter in the pronephros (72), allowing for in vivo fluorescence imaging of the cystic pronephros.

Nephronophthisis (NPHP), an autosomal recessive cystic kidney disease, represents the most frequent genetic cause of ESRD in the first three decades of life (55). Nephronophthisis 
can be accompanied by anomalies in other organs, such as cerebellar vermis hypoplasia, laterality defects, intellectual disability, shortening of bones, retinal degeneration, and hepatobiliary disease (56). These features are represented in a variety of syndromes, including Senior-Løken syndrome, Joubert syndrome, Bardet-Biedl syndrome, and Jeune asphyxiating thoracic dystrophy $(73,74)$. To date, NPHP-causing mutations have been identified in more than 20 genes (56). Morpholino knockdown in zebrafish has been performed for $n p h p 2$ to 6 (75-83) and nphp11 (84). Zebrafish mutants for arl13b/sco hi459 (85), ahil ${ }^{\text {lrit6 }}$ (86), and $c c 2 d 2 a$ (87) develop pronephric cysts to varying degrees and serve as models for Joubert syndromerelated disease.

Intraflagellar transport (IFT) proteins are essential for the development and maintenance of motile and sensory cilia and localize to the cilium, basal body, and/or centrosome (88). Several zebrafish ift mutants demonstrating renal cysts were identified by forward genetic screens $(63,89)$. IFT80 mutations underlie a subset of Jeune asphyxiating thoracic dystrophy cases, of which $20 \%$ are associated with kidney abnormalities including renal cysts (90). Ift80 morphants show a dose-dependent phenotype with strong body curvature, large kidney cyst, and pericardial edema. IFT172 mutations were initially reported in Jeune and Mainzer-Saldino syndromes, but have also been observed in patients with Bardet-Biedl syndrome $(91,92)$. Zebrafish mutants and morphants for ift 172 resemble these phenotypes, with renal cysts readily detectable in brightfield images (91). In our work, we have shown that morpholino knockdown of ift80 and ift172 in $\mathrm{Tg}(w t 1 b: e g f p)$ with fluorescently labeled kidney structures allow for visualization of pronephric cysts, providing a model system for large-scale chemical screening studies to identify chemical modifiers of cyst formation (93).

\section{CHEMICAL SCREENING IN ZEBRAFISH-TECHNICAL ASPECTS AND CONSIDERATIONS}

The zebrafish can cost-effectively bridge the gap between high-throughput experimentation in cellular models lacking physiological context and low-throughput models such as rodents that are closer to human biology $(12,13,23,94)$. The optically transparent embryos and larvae fit into wells of microtiter plates rendering them amenable for automated microscopy applications using existing screening technologies $(12,13,17,23)$. Due to accessibility to genetic manipulation (37, 95), a plethora of zebrafish transgenic and mutant lines has been generated (www.zfin.org, www.ezrc.kit.edu, www.zebrafish.org) (96), complemented by transient labeling, knockdown and genome-editing techniques (97). This provides an extraordinary rich toolkit to model and visualize the biological processes underlying development and disease. Several transgenic lines labeling pronephric structures such as podocytes $(98,99)$, tubules, and ducts $(98,100-106)$ or both (72) have been established. In combination with genetic alteration, either by transient gene knockdown using antisense morpholino oligos or by genome-editing technologies, these lines can mimic e.g.,
ARPKD (71), ADPKD (107), and other cystic kidney diseases (93, 108) and enable in vivo fluorescence microscopy of the diseased pronephros. Although controversies exist regarding the use of morphants generated by morpholino knockdown (109-113), they remain a valuable tool in altering target gene expression, provided that all mandatory control experiments to validate the observed disease-associated phenotypes have been conducted $(110,111)$.

To our knowledge, large-scale screening experiments evaluating fluorescent pronephric phenotypes in models of genetic kidney diseases have not been demonstrated. In a chemical modifier screen using a custom library of 115 compounds in $p k d 2^{h i 4166}$ and ift172 $2^{\text {hi2211 }}$ mutants displaying renal cysts (114), morphological parameters such as body axis curvature and/or laterality defects were scored. Histone deacetylase inhibitors Tricostatin A and valproic acid attenuated these phenotypes, and cyst size-reducing effects were confirmed in secondary assays. Additionally, a chemical screen of $\sim 2,000$ compounds identified histone deacetylase inhibitors to expand the pool of embryonic renal progenitor cells (115), a mechanism presumably involved in regeneration following acute kidney injury.

In combination with automated microscopy (116), zebrafish disease model systems allow performing large-scale phenotypic whole organism screening assays $(117,118)$. Phenotypic readouts encompass survival rates, overall morphology, physiological parameters, cell- and tissuespecific phenotypes, reporter gene expression patterns, and behavioral phenotypes $(25,27,93,119-123)$. Phenotypic screens within the context of a live vertebrate provide significant advantage over classical target-based in vitro assays as they do not require a priori knowledge about biochemical pathways affected, thus allowing unbiased identification of drug candidates or toxicological effects of substances. Furthermore, they intrinsically involve potential contributions of biodistribution, metabolism, and pharmacokinetics $(1,12,13,17,95,124)$.

Prior to large-scale zebrafish experiments careful planning and preparatory experiments are required to generate robust protocols and tailor conditions toward desired readouts in screening compatible disease models. In brief, handling of thousands of embryos causes logistical challenges, thus protocols for animal husbandry, micromanipulation, embryo culture, and treatment (e.g., anesthesia), and sample handling must be established. When image-based assays are carried out the usage of pigmentation mutant strains (e.g., casper line) or chemical treatment (e.g., 1-phenyl-2-thiourea, PTU) to block pigment formation is often necessary to adequately visualize internal structures. Moreover, to minimize false positive and negative results, non-specific developmental toxicity or off-target effects, control experiments must be carried out to titrate required compound concentration ranges as well as the treatment period during embryonic development. Importantly, controls should also be continuously carried out as a reference readout to benchmark observed phenotypic effects and normalize experimental variation. Finally, image acquisition routines must be balanced with analysis 
A

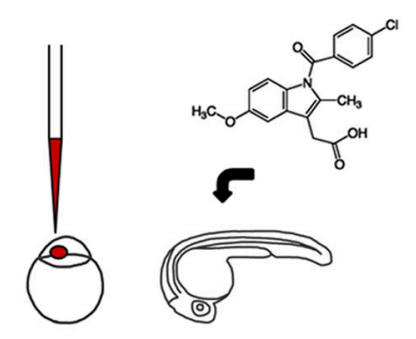

C

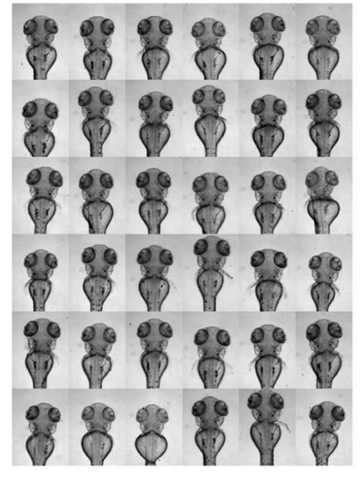

B
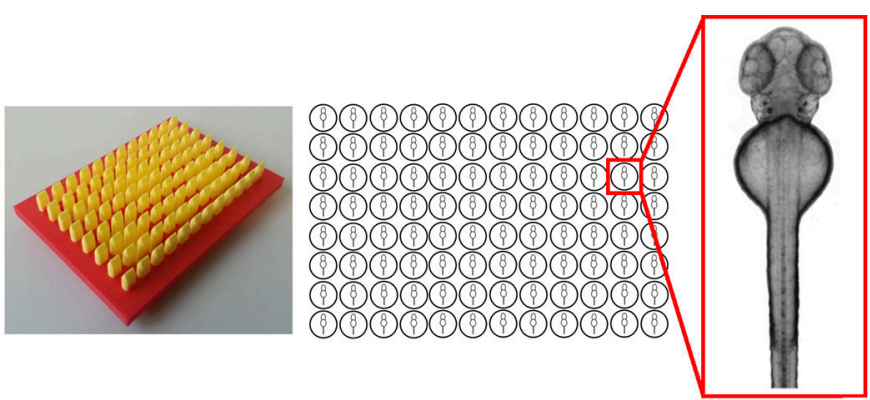

D

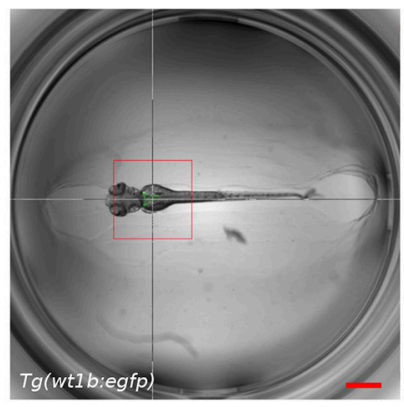

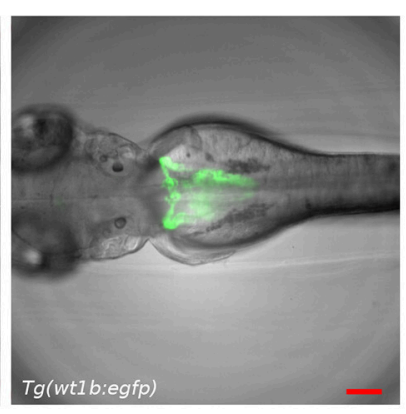

E

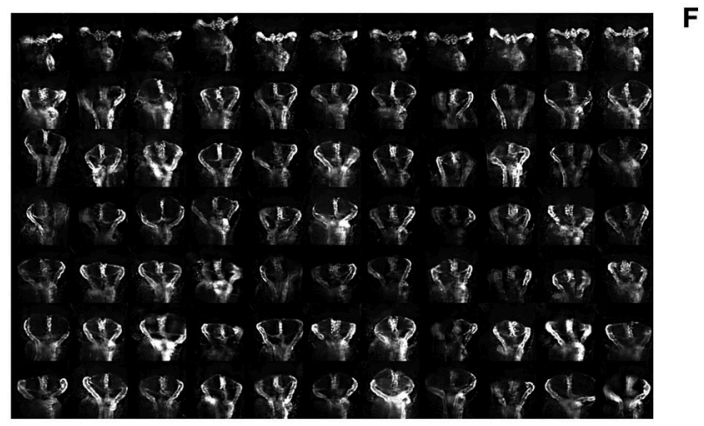

cystic area

(pixel)

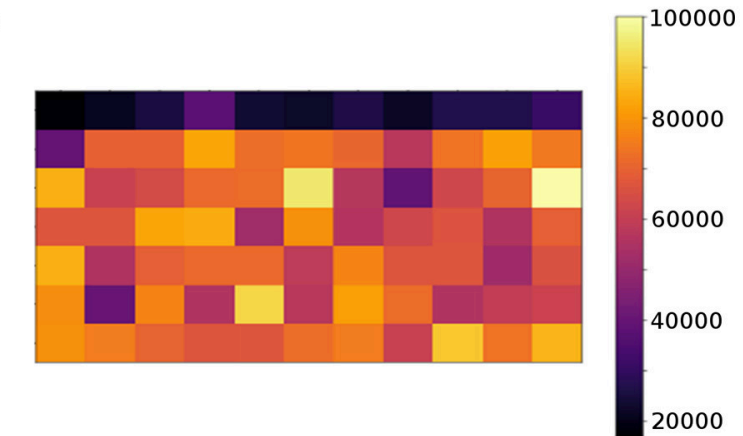

FIGURE 2 | Overview of screening workflows for organ specific phenotypic screening in zebrafish. Shown are examples from our screening work that illustrate the automatic acquisition of higher resolution datasets of embryonic kidneys in zebrafish embryos. (A) Experimental manipulation of embryos prior to mounting and automated imaging such as microinjection or compound treatment. (B) Mounting of zebrafish embryos in agarose coated microtiter plates generated using 3D printed orientation tools. Agarose layers contain cavities allowing for consistent alignment and orientation of specimen. (C) Automated acquisition of standardized views (e.g., dorsal) of zebrafish embryos arrayed in microtiter plates. (D) Automated acquisition of multidimensional image datasets using smart imaging techniques. Pronephric areas of the $T g(w t$ b:egfp) zebrafish transgenic line are detected in low resolution datasets using image processing tools and are subsequently imaged at higher resolution. The hair cross indicates the detected position and the bounding box the field of view in subsequent higher resolution imaging. Scale bars indicate $600 \mu \mathrm{m}$ (left panel) or $150 \mu \mathrm{m}$ (right panel). (E) Detailed visualization of kidney regions enabling scoring of kidney phenotypes. Shown are wildtype (first row) or cystic (other rows) kidneys of $72 \mathrm{hpf} T g(w t 1 b: e g f p)$ embryos. (F) Automated quantitative analysis and phenotypic scoring using image processing techniques. Heatmap shows quantitative measurements of cystic areas as shown in (E). Figure panels are taken or modified from Westhoff et al. (93), Wittbrodt et al. (125), Pandey et al. (unpublished), and www.acquifer.de.

needs to ensure effective and robust scoring of phenotypic alterations.

Despite its amenability to large-scale experimentation, the full exploitation of the zebrafish model in screening assays is often hampered. While sample manipulation can be scaled efficiently, large-scale imaging, and phenotypic scoring remains challenging as available screening methodologies are usually optimized for in vitro assays (Figure 2A) (126). In comparison to cellular models, zebrafish embryos are large three-dimensional objects of complex morphology leading to random orientation of embryos within wells of microtiter plates $(126,127)$. This can obscure the view on target structures and leads to the generation of non-standardized image data. Therefore, novel sample preparations or automation strategies are needed, as it is unfeasible to upscale classical zebrafish mounting techniques. In our work, we developed orientation tools 
allowing the generation of agarose cavities within wells of microtiter plates for consistent positioning and orientation of zebrafish embryos (Figure 2B) (25, 93, 125). This enables the automated acquisition of consistent views of 48-96 hpf zebrafish larvae in large-scale screening scenarios (Figure 2C). For instance, we employed that methodology for imaging of embryonic kidneys in automated large-scale microscopy assays to score for morphological alterations of the pronephros upon compound exposure $(93,125,128)$ (Westhoff et al. unpublished data) or capture phenotypic changes in cystic kidney disease models (129) (Pandey et al., unpublished data). Other more complex technical solutions employ microfluidic systems that combine automated detection and rotational orientation within glass capillaries followed by microscopic imaging $(127,130)$.

To date, the vast majority of zebrafish screens employ low magnification to capture the entire zebrafish embryo body, followed by subsequent analysis of phenotypic changes $(13,131)$. However, this significantly attenuates the power of using a fully developed live vertebrate embryo as in vivo visualization of morphological, physiological or genetic events on the cell- or tissue-specific level is hampered. The widespread usage of low resolution assays is largely due to the impracticality of positioning the regions of interest (ROI) within the small field of views of higher magnification objectives in combination with fixed scan-field coordinates of automated microscopes. Additionally, the spatiotemporal location of ROIs within the embryo body might be variable or unpredictable. To overcome that limitation, technologies have been developed that allow the automatic centering of ROIs in front of objective lenses of microscopes. Microfluidic systems $(127,130)$ can fulfill that requirement but usually require rather complex setups and are potentially challenged when overall morphological changes occur, or developmental and disease-associated processes are observed in time-lapse experiments. Several automated microscopy solutions for microplate-based screening have been reported that allow to teach or detect the position of ROIs followed by automatic centering and multidimensional image acquisition (126, 132134). This can be an expert operator manually selecting target structures for subsequent automated imaging or more advanced methods employing automatic detection by image processing. These automated smart imaging approaches are based on interfacing the imaging device with external software tools that automatically detect coordinates of features of interest and send back machine commands containing instructions for re-centering, higher resolution imaging, or tracking of target structures. While several solutions have been reported, their application is usually restricted to cellular models and they are often characterized by a high level of complexity requiring expert knowledge in image processing, general programming and hardand software interfacing. Therefore, to enable a widespread usage of such toolsets novel developments are needed that provide a simplified access to biomedical researchers. To this extent, we have developed a robotic microscopy platform (www.acquifer. de) with a smart imaging interface that allows to manually select ROIs, or to use any image processing software to send back human-readable script commands to the imaging device. We utilize this technique to e.g., acquire high-resolution datasets of cystic kidneys in a genetic zebrafish disease model to screen for modifiers of cystogenesis (Figures 2D-F) (129) (Pandey et al., unpublished data).

Due to the wide variety of potential zebrafish screening assays and thus phenotypic readouts there are myriad of potential quantitative descriptors that can be extracted from image-based datasets. This can include fluorescence intensity, morphological descriptors, or dynamic parameters and ranges from simple whole embryo signal intensity to spatiotemporal activity of fluorescent reporters or tissue dynamics and beyond. For instance, advanced segmentation techniques were used in the $T g(c d h 17: e g f p)^{p t 305}$ zebrafish line to detect the fluorescently labeled tubular cells of the kidney (105). A full discussion of analysis strategies and development of automated image processing pipelines is beyond the scope of this manuscript (135). However, as post-acquisition analysis strategies are of vital importance for the success of any screening assay, the design of scoring pipelines needs careful consideration at early stages of experimental planning.

\section{CONCLUSIONS}

Phenotype-based, cost-effective whole-organism chemical screening in zebrafish offers a variety of advantages including the identification of disease-modifying drugs without knowledge of a validated target, the potential to identify compounds with polypharmacological efficacy, and the simultaneous assessment of compound efficacy, toxicity, biodistribution, and pharmacokinetics within a vertebrate model system. While a growing number of genes are being identified to cause human kidney diseases, therapeutic options to combat these diseases are often absent. Ideally, the use of genetically modified zebrafish mimicking human genetic disorders in conjunction with kidney-specific transgenic reporter lines or in conjunction with fluorescently-labeled functional reporter lines (or other secondary readouts), permit the implementation of chemical screening for disease-modifying substances in the field of genetic kidney diseases.

\section{AUTHOR CONTRIBUTIONS}

All authors listed have made a substantial, direct, and intellectual contribution to the work, and approved it for publication.

\section{ACKNOWLEDGMENTS}

We thank Franz Schaefer (University Children's Hospital Heidelberg), Felix Loosli (Karlsruhe Institute of Technology) and Jochen Wittbrodt (Centre for Organismal Studies (COS) Heidelberg) for general support. This work was partially funded by the RENALTRACT ITN project, that has received funding from the European Union's Horizon 2020 research and innovation programme under the Marie Sklodowska-Curie grant agreement $\mathrm{N}^{\circ} 642937$. JHW has received funding from 
Peter-Stiftung für die Nierenwissenschaft and Doktor Robert Pfleger-Stiftung. We acknowledge financial support by Deutsche Forschungsgemeinschaft within the funding programme Open
Access Publishing, by the Baden-Württemberg Ministry of Science, Research and the Arts and by Ruprecht-KarlsUniversität Heidelberg.

\section{REFERENCES}

1. Lieschke GJ, Currie PD. Animal models of human disease: zebrafish swim into view. Nat Rev Genet. (2007) 8:353-67. doi: 10.1038/nrg2091

2. Dooley K, Zon LI. Zebrafish: a model system for the study of human disease. Curr Opin Genet Dev. (2000) 10:252-6. doi: 10.1016/S0959-437X(00) 00074-5

3. Howe K, Clark MD, Torroja CF, Torrance J, Berthelot C, Muffato M, et al. The zebrafish reference genome sequence and its relationship to the human genome. Nature (2013) 496:498-503. doi: 10.1038/nature12111

4. Ota S, Kawahara A. Zebrafish: a model vertebrate suitable for the analysis of human genetic disorders. Congenit Anom. (2014) 54:8-11. doi: $10.1111 /$ cga. 12040

5. Cong L, Ran FA, Cox D, Lin S, Barretto R, Habib N, et al. Multiplex genome engineering using CRISPR/Cas systems. Science (2013) 339:819-23. doi: 10.1126/science. 1231143

6. Mali P, Yang L, Esvelt KM, Aach J, Guell M, DiCarlo JE, et al. RNAguided human genome engineering via Cas9. Science (2013) 339:823-6. doi: $10.1126 /$ science. 1232033

7. Swanhart LM, Cosentino CC, Diep CQ, Davidson AJ, de Caestecker M, Hukriede NA. Zebrafish kidney development: basic science to translational research. Birth Defects Res C Embryo Today (2011) 93:141-56. doi: 10.1002/bdrc.20209

8. Wingert RA, Selleck R, Yu J, Song HD, Chen Z, Song A, et al. The $c d x$ genes and retinoic acid control the positioning and segmentation of the zebrafish pronephros. PLoS Genet. (2007) 3:1922-38. doi: 10.1371/journal.pgen.0030189

9. Morales EE, Wingert RA. Zebrafish as a model of kidney disease. Results Probl Cell Differ. (2017) 60:55-75. doi: 10.1007/978-3-319-51436-9_3

10. Driever W, Solnica-Krezel L, Schier AF, Neuhauss SC, Malicki J, Stemple DL, et al. A genetic screen for mutations affecting embryogenesis in zebrafish. Development (1996) 123:37-46.

11. Drummond IA, Majumdar A, Hentschel H, Elger M, Solnica-Krezel L, Schier $\mathrm{AF}$, et al. Early development of the zebrafish pronephros and analysis of mutations affecting pronephric function. Development (1998) 125:4655-67.

12. MacRae CA, Peterson RT. Zebrafish as tools for drug discovery. Nat Rev Drug Discov. (2015) 14:721-31. doi: 10.1038/nrd4627

13. Rennekamp AJ, Peterson RT. 15 years of zebrafish chemical screening. Curr Opin Chem Biol. (2015) 24:58-70. doi: 10.1016/j.cbpa.2014.10.025

14. Shah AN, Davey CF, Whitebirch AC, Miller AC, Moens CB. Rapid reverse genetic screening using CRISPR in zebrafish. Nat Methods (2015) 12:535-40. doi: $10.1038 /$ nmeth. 3360

15. Dang M, Fogley R, Zon LI. Identifying novel cancer therapies using chemical genetics and zebrafish. Adv Exp Med Biol. (2016) 916:103-24. doi: 10.1007/978-3-319-30654-4 5

16. Sipes NS, Padilla S, Knudsen TB. Zebrafish: as an integrative model for twenty-first century toxicity testing. Birth Defects Res C Embryo Today (2011) 93:256-67. doi: 10.1002/bdrc.20214

17. Yang L, Ho NY, Alshut R, Legradi J, Weiss C, Reischl M, et al. Zebrafish embryos as models for embryotoxic and teratological effects of chemicals. Reprod Toxicol. (2009) 28:245-53. doi: 10.1016/j.reprotox.2009.04.013

18. Sullivan C, Matty MA, Jurczyszak D, Gabor KA, Millard PJ, Tobin DM, et al. Infectious disease models in zebrafish. Methods Cell Biol. (2017) 138:101-36. doi: 10.1016/bs.mcb.2016. 10.005

19. Astin JW, Keerthisinghe P, Du L, Sanderson LE, Crosier KE, Crosier PS, et al. Innate immune cells and bacterial infection in zebrafish. Methods Cell Biol. (2017) 138:31-60. doi: 10.1016/bs.mcb.2016.08.002

20. Kessler M, Rottbauer W, Just S. Recent progress in the use of zebrafish for novel cardiac drug discovery. Expert Opin Drug Discov. (2015) 10:1231-41. doi: $10.1517 / 17460441.2015 .1078788$

21. Vazao H, Rosa S, Barata T, Costa R, Pitrez PR, Honorio I, et al. Highthroughput identification of small molecules that affect human embryonic vascular development. Proc Natl Acad Sci USA. (2017) 114:E3022-31. doi: $10.1073 /$ pnas. 1617451114

22. Eimon PM, Rubinstein AL. The use of in vivo zebrafish assays in drug toxicity screening. Expert Opin Drug Metab Toxicol. (2009) 5:393-401. doi: $10.1517 / 17425250902882128$

23. Brady CA, Rennekamp AJ, Peterson RT. Chemical screening in Zebrafish. Methods Mol Biol. (2016) 1451:3-16. doi: 10.1007/978-1-4939-3771-4_1

24. Baxendale S, van Eeden F, Wilkinson R. The power of Zebrafish in personalised medicine. Adv Exp Med Biol. (2017) 1007:179-97. doi: 10.1007/978-3-319-60733-7_10

25. Gehrig J, Reischl M, Kalmar E, Ferg M, Hadzhiev Y, Zaucker A, et al. Automated high-throughput mapping of promoter-enhancer interactions in zebrafish embryos. Nat Methods (2009) 6:911-6. doi: 10.1038/nmeth.1396

26. Bruni G, Lakhani P, Kokel D. Discovering novel neuroactive drugs through high-throughput behavior-based chemical screening in the zebrafish. Front Pharmacol. (2014) 5:153. doi: 10.3389/fphar.2014.00153

27. Rihel J, Schier AF. Behavioral screening for neuroactive drugs in zebrafish. Dev Neurobiol. (2012) 72:373-85. doi: 10.1002/dneu.20910

28. North TE, Goessling W, Walkley CR, Lengerke C, Kopani KR, Lord AM, et al. Prostaglandin E2 regulates vertebrate haematopoietic stem cell homeostasis. Nature (2007) 447:1007-11. doi: 10.1038/nature05883

29. Eckardt KU, Coresh J, Devuyst O, Johnson RJ, Kottgen A, Levey AS, et al. Evolving importance of kidney disease: from subspecialty to global health burden. Lancet (2013) 382:158-69. doi: 10.1016/S0140-6736(13)60439-0

30. Drummond IA. Zebrafish kidney development. Methods Cell Biol. (2004) 76:501-30. doi: 10.1016/S0091-679X(04)76023-9

31. Desgrange A, Cereghini S. Nephron patterning: lessons from Xenopus, Zebrafish, and Mouse studies. Cells (2015) 4:483-99. doi: $10.3390 /$ cells 4030483

32. Ebarasi L, Oddsson A, Hultenby K, Betsholtz C, Tryggvason K. Zebrafish: a model system for the study of vertebrate renal development, function, and pathophysiology. Curr Opin Nephrol Hypertens. (2011) 20:416-24. doi: 10.1097/MNH.0b013e3283477797

33. Drummond IA. The zebrafish pronephros: a genetic system for studies of kidney development. Pediatr Nephrol. (2000) 14:428-35. doi: $10.1007 / \mathrm{s} 004670050788$

34. Wingert RA, Davidson AJ. The zebrafish pronephros: a model to study nephron segmentation. Kidney Int. (2008) 73:1120-7. doi: $10.1038 / \mathrm{ki} .2008 .37$

35. Anzenberger U, Bit-Avragim N, Rohr S, Rudolph F, Dehmel B, Willnow TE, et al. Elucidation of megalin/LRP2-dependent endocytic transport processes in the larval zebrafish pronephros. J Cell Sci. (2006) 119(Pt 10):2127-37. doi: $10.1242 /$ jcs. 02954

36. Nichane M, Van Campenhout C, Pendeville H, Voz ML, Bellefroid EJ. The $\mathrm{Na}+/ \mathrm{PO} 4$ cotransporter SLC20A1 gene labels distinct restricted subdomains of the developing pronephros in Xenopus and zebrafish embryos. Gene Expr Patterns (2006) 6:667-72. doi: 10.1016/j.modgep.2006.01.005

37. Santoriello C, Zon LI. Hooked! Modeling human disease in zebrafish. J Clin Invest. (2012) 122:2337-43. doi: 10.1172/JCI60434

38. Kramer-Zucker AG, Wiessner S, Jensen AM, Drummond IA. Organization of the pronephric filtration apparatus in zebrafish requires nephrin, podocin and the FERM domain protein mosaic eyes. Dev Biol. (2005) 285:316-29. doi: 10.1016/j.ydbio.2005.06.038

39. Fukuyo Y, Nakamura T, Bubenshchikova E, Powell R, Tsuji T, Janknecht $\mathrm{R}$, et al. Nephrin and podocin functions are highly conserved between the zebrafish pronephros and mammalian metanephros. Mol Med Rep. (2014) 9:457-65. doi: $10.3892 / \mathrm{mmr} .2013 .1844$

40. Niaudet P, Gubler MC. WT1 and glomerular diseases. Pediatr Nephrol. (2006) 21:1653-60. doi: 10.1007/s00467-006-0208-1 
41. Hall G, Gbadegesin RA, Lavin P, Wu G, Liu Y, Oh EC et al. A novel missense mutation of Wilms' Tumor 1 causes autosomal dominant FSGS. J Am Soc Nephrol. (2015) 26:831-43. doi: 10.1681/ASN.2013101053

42. Gbadegesin R, Hinkes BG, Hoskins BE, Vlangos CN, Heeringa SF, Liu $\mathrm{J}$, et al. Mutations in PLCE1 are a major cause of isolated diffuse mesangial sclerosis (IDMS). Nephrol Dial Transplant. (2008) 23:1291-7. doi: $10.1093 / \mathrm{ndt} / \mathrm{gfm} 759$

43. Hinkes B, Wiggins RC, Gbadegesin R, Vlangos CN, Seelow D, Nurnberg $\mathrm{G}$, et al. Positional cloning uncovers mutations in PLCE1 responsible for a nephrotic syndrome variant that may be reversible. Nat Genet. (2006) 38:1397-405. doi: 10.1038/ng1918

44. Ashraf S, Gee HY, Woerner S, Xie LX, Vega-Warner V, Lovric S, et al. ADCK4 mutations promote steroid-resistant nephrotic syndrome through CoQ10 biosynthesis disruption. J Clin Invest. (2013) 123:5179-89. doi: 10.1172/JCI69000

45. Gee HY, Zhang F, Ashraf S, Kohl S, Sadowski CE, Vega-Warner V, et al. KANK deficiency leads to podocyte dysfunction and nephrotic syndrome. J Clin Invest. (2015) 125:2375-84. doi: 10.1172/JCI79504

46. Ebarasi L, Ashraf S, Bierzynska A, Gee HY, McCarthy HJ, Lovric S, et al. Defects of CRB2 cause steroid-resistant nephrotic syndrome. Am J Hum Genet. (2015) 96:153-61. doi: 10.1016/j.ajhg.2014.11.014

47. Miyake N, Tsukaguchi H, Koshimizu E, Shono A, Matsunaga S, Shiina M, et al. Biallelic mutations in nuclear pore complex subunit NUP107 cause earlychildhood-onset steroid-resistant nephrotic syndrome. Am J Hum Genet. (2015) 97:555-66. doi: 10.1016/j.ajhg.2015.08.013

48. Gee HY, Saisawat P, Ashraf S, Hurd TW, Vega-Warner V, Fang H, et al. ARHGDIA mutations cause nephrotic syndrome via defective RHO GTPase signaling. J Clin Invest. (2013) 123:3243-53. doi: 10.1172/JCI69134

49. Hill AJ, Bello SM, Prasch AL, Peterson RE, Heideman W. Water permeability and TCDD-induced edema in zebrafish early-life stages. Toxicol Sci. (2004) 78:78-87. doi: 10.1093/toxsci/kfh056

50. Rider SA, Tucker CS, del-Pozo J, Rose KN, MacRae CA, Bailey MA, et al. Techniques for the in vivo assessment of cardio-renal function in zebrafish (Danio rerio) larvae. J Physiol. (2012) 590(Pt 8):1803-9. doi: 10.1113/jphysiol.2011.224352

51. Kotb AM, Muller T, Xie J, Anand-Apte B, Endlich K, Endlich N. Simultaneous assessment of glomerular filtration and barrier function in live zebrafish. Am J Physiol Renal Physiol. (2014) 307:F1427-34. doi: 10.1152/ajprenal.00029.2014

52. Hentschel DM, Park KM, Cilenti L, Zervos AS, Drummond I, Bonventre JV. Acute renal failure in zebrafish: a novel system to study a complex disease. Am J Physiol Renal Physiol. (2005) 288:F923-9. doi: 10.1152/ajprenal.00386.2004

53. Hanke N, King BL, Vaske B, Haller H, Schiffer M. A Fluorescence-based assay for proteinuria screening in larval zebrafish (Danio rerio). Zebrafish (2015) 12:372-6. doi: 10.1089/zeb.2015.1093

54. Zhou W, Hildebrandt F. Inducible podocyte injury and proteinuria in transgenic zebrafish. J Am Soc Nephrol. (2012). 23:1039-47. doi: 10.1681/ASN.2011080776

55. Hildebrandt F, Zhou W. Nephronophthisis-associated ciliopathies. J Am Soc Nephrol. (2007) 18:1855-71. doi: 10.1681/ASN.2006121344

56. Arts $\mathrm{HH}$, Knoers NV. Current insights into renal ciliopathies: what can genetics teach us? Pediatr Nephrol. (2013) 28:863-74. doi: 10.1007/s00467-012-2259-9

57. Hildebrandt F, Otto E. Cilia and centrosomes: a unifying pathogenic concept for cystic kidney disease? Nat Rev Genet. (2005) 6:928-40. doi: $10.1038 / \operatorname{nrg} 1727$

58. Watnick T, Germino G. From cilia to cyst. Nat Genet. (2003) 34:355-6. doi: 10.1038/ng0803-355

59. Hostetter CL, Sullivan-Brown JL, Burdine RD. Zebrafish pronephros: a model for understanding cystic kidney disease. Dev Dyn. (2003) 228:514-22. doi: 10.1002/dvdy.10371

60. Liu S, Lu W, Obara T, Kuida S, Lehoczky J, Dewar K, et al. A defect in a novel Nek-family kinase causes cystic kidney disease in the mouse and in zebrafish. Development (2002) 129:5839-46. doi: 10.1242/dev. 00173

61. Low SH, Vasanth S, Larson CH, Mukherjee S, Sharma N, Kinter MT, et al. Polycystin-1, STAT6, and P100 function in a pathway that transduces ciliary mechanosensation and is activated in polycystic kidney disease. Dev Cell (2006) 10:57-69. doi: 10.1016/j.devcel.2005.12.005

62. Otto EA, Schermer B, Obara T, O’Toole JF, Hiller KS, Mueller AM, et al. Mutations in INVS encoding inversin cause nephronophthisis type 2, linking renal cystic disease to the function of primary cilia and left-right axis determination. Nat Genet. (2003) 34:413-20. doi: 10.1038/ng1217

63. Sun Z, Amsterdam A, Pazour GJ, Cole DG, Miller MS, Hopkins N. A genetic screen in zebrafish identifies cilia genes as a principal cause of cystic kidney. Development (2004) 131:4085-93. doi: 10.1242/dev.01240

64. Tobin JL, Beales PL. Restoration of renal function in zebrafish models of ciliopathies. Pediatr Nephrol. (2008) 23:2095-9. doi: 10.1007/s00467-008-0898-7

65. Kramer-Zucker AG, Olale F, Haycraft CJ, Yoder BK, Schier AF, Drummond IA. Cilia-driven fluid flow in the zebrafish pronephros, brain and Kupffer's vesicle is required for normal organogenesis. Development (2005) 132:190721. doi: $10.1242 / \mathrm{dev} .01772$

66. Satir P, Christensen ST. Structure and function of mammalian cilia. Histochem Cell Biol. (2008) 129:687-93. doi: 10.1007/s00418-008-0416-9

67. Le Corre S, Eyre D, Drummond IA. Modulation of the secretory pathway rescues zebrafish polycystic kidney disease pathology. J Am Soc Nephrol. (2014) 25:1749-59. doi: 10.1681/ASN.2013101060

68. Obara T, Mangos S, Liu Y, Zhao J, Wiessner S, Kramer-Zucker AG, et al. Polycystin-2 immunolocalization and function in zebrafish. J Am Soc Nephrol. (2006) 17:2706-18. doi: 10.1681/ASN.2006040412

69. Schottenfeld J, Sullivan-Brown J, Burdine RD. Zebrafish curly up encodes a $\mathrm{Pkd} 2$ ortholog that restricts left-side-specific expression of southpaw. Development (2007) 134:1605-15. doi: 10.1242/dev.02827

70. Bergmann C, Senderek J, Kupper F, Schneider F, Dornia C, Windelen E, et al. PKHD1 mutations in autosomal recessive polycystic kidney disease (ARPKD). Hum Mutat. (2004) 23:453-63. doi: 10.1002/humu.20029

71. Lu H, Galeano MCR, Ott E, Kaeslin G, Kausalya PJ, Kramer C, et al. Mutations in DZIP1L, which encodes a ciliary-transition-zone protein, cause autosomal recessive polycystic kidney disease. Nat Genet. (2017) 49:1025-34. doi: 10.1038/ng.3871

72. Perner B, Englert C, Bollig F. The Wilms tumor genes wtla and wt1b control different steps during formation of the zebrafish pronephros. Dev Biol. (2007) 309:87-96. doi: 10.1016/j.ydbio.2007. 06.022

73. Bergmann C. Educational paper: ciliopathies. Eur J Pediatr. (2012) 171:1285300. doi: 10.1007/s00431-011-1553-z

74. Hildebrandt F, Benzing T, Katsanis N. Ciliopathies. N Engl J Med. (2011) 364:1533-43. doi: 10.1056/NEJMra1010172

75. Borgal L, Habbig S, Hatzold J, Liebau MC, Dafinger C, Sacarea I, et al. The ciliary protein nephrocystin-4 translocates the canonical Wnt regulator Jade1 to the nucleus to negatively regulate beta-catenin signaling. J Biol Chem. (2012) 287:25370-80. doi: 10.1074/jbc.M112.385658

76. Burckle C, Gaude HM, Vesque C, Silbermann F, Salomon R, Jeanpierre $\mathrm{C}$, et al. Control of the Wnt pathways by nephrocystin-4 is required for morphogenesis of the zebrafish pronephros. Hum Mol Genet. (2011) 20:2611-27. doi: 10.1093/hmg/ddr164

77. French VM, van de Laar IM, Wessels MW, Rohe C, RoosHesselink JW, Wang G, et al. NPHP4 variants are associated with pleiotropic heart malformations. Circ Res. (2012) 110:1564-74. doi: 10.1161/CIRCRESAHA.112.269795

78. Hoff S, Halbritter J, Epting D, Frank V, Nguyen TM, van Reeuwijk J, et al. ANKS6 is a central component of a nephronophthisis module linking NEK8 to INVS and NPHP3. Nat Genet. (2013) 45:951-6. doi: 10.1038/ng.2681

79. Schafer T, Putz M, Lienkamp S, Ganner A, Bergbreiter A, Ramachandran $\mathrm{H}$, et al. Genetic and physical interaction between the NPHP5 and NPHP6 gene products. Hum Mol Genet. (2008) 17:3655-62. doi: 10.1093/hmg/ ddn 260

80. Simons M, Gloy J, Ganner A, Bullerkotte A, Bashkurov M, Kronig C, et al. Inversin, the gene product mutated in nephronophthisis type II, functions as a molecular switch between Wnt signaling pathways. Nat Genet. (2005) 37:537-43. doi: 10.1038/ng1552

81. Slanchev K, Putz M, Schmitt A, Kramer-Zucker A, Walz G. Nephrocystin4 is required for pronephric duct-dependent cloaca formation in zebrafish. Hum Mol Genet. (2011) 20:3119-28. doi: 10.1093/hmg/ddr214 
82. Zhao C, Malicki J. Nephrocystins and MKS proteins interact with IFT particle and facilitate transport of selected ciliary cargos. EMBO J. (2011) 30:2532-44. doi: 10.1038/emboj.2011.165

83. Zhou W, Dai J, Attanasio M, Hildebrandt F. Nephrocystin-3 is required for ciliary function in zebrafish embryos. Am J Physiol Renal Physiol. (2010) 299:F55-62. doi: 10.1152/ajprenal.00043.2010

84. Adams M, Simms RJ, Abdelhamed Z, Dawe HR, Szymanska K, Logan CV, et al. A meckelin-filamin A interaction mediates ciliogenesis. Hum Mol Genet. (2012) 21:1272-86. doi: 10.1093/hmg/ddr557

85. Duldulao NA, Lee S, Sun Z. Cilia localization is essential for in vivo functions of the Joubert syndrome protein Arl13b/Scorpion. Development (2009) 136:4033-42. doi: 10.1242/dev.036350

86. Lessieur EM, Fogerty J, Gaivin RJ, Song P, Perkins BD. The ciliopathy gene ahil is required for zebrafish cone photoreceptor outer segment morphogenesis and survival. Invest Ophthalmol Vis Sci. (2017) 58:448-60. doi: 10.1167 /iovs.16-20326

87. Bachmann-Gagescu R, Phelps IG, Stearns G, Link BA, Brockerhoff SE, Moens $\mathrm{CB}$, et al. The ciliopathy gene cc $2 \mathrm{~d} 2$ a controls zebrafish photoreceptor outer segment development through a role in Rab8-dependent vesicle trafficking. Hum Mol Genet. (2011) 20:4041-55. doi: 10.1093/hmg/ddr332

88. Rosenbaum JL, Witman GB. Intraflagellar transport. Nat Rev Mol Cell Biol. (2002) 3:813-25. doi: 10.1038/nrm952

89. Amsterdam A, Nissen RM, Sun Z, Swindell EC, Farrington S, Hopkins N. Identification of 315 genes essential for early zebrafish development. Proc Natl Acad Sci USA. (2004) 101:12792-7. doi: 10.1073/pnas.0403929101

90. de Vries J, Yntema JL, van Die CE, Crama N, Cornelissen EA, Hamel BC. Jeune syndrome: description of 13 cases and a proposal for follow-up protocol. Eur J Pediatr. (2010) 169:77-88. doi: 10.1007/s00431-009-0991-3

91. Halbritter J, Bizet AA, Schmidts M, Porath JD, Braun DA, Gee HY, et al. Defects in the IFT-B component IFT172 cause Jeune and MainzerSaldino syndromes in humans. Am J Hum Genet. (2013) 93:915-25. doi: 10.1016/j.ajhg.2013.09.012

92. Schaefer E, Stoetzel C, Scheidecker S, Geoffroy V, Prasad MK, Redin $\mathrm{C}$, et al. Identification of a novel mutation confirms the implication of IFT172 (BBS20) in Bardet-Biedl syndrome. J Hum Genet. (2016) 61:447-50. doi: 10.1038/jhg.2015.162

93. Westhoff JH, Giselbrecht S, Schmidts M, Schindler S, Beales PL, Tonshoff B, et al. Development of an automated imaging pipeline for the analysis of the zebrafish larval kidney. PLOS ONE (2013) 8:e82137. doi: 10.1371/journal.pone.0082137

94. Veldman MB, Lin S. Zebrafish as a developmental model organism for pediatric research. Pediatr Res. (2008) 64:470-6. doi: 10.1203/PDR.0b013e318186e609

95. Phillips JB, Westerfield M. Zebrafish models in translational research: tipping the scales toward advancements in human health. Dis Model Mech. (2014) 7:739-43. doi: 10.1242/dmm.015545

96. Geisler R, Borel N, Ferg M, Maier JV, Strahle U. Maintenance of Zebrafish Lines at the European Zebrafish Resource Center. Zebrafish (2016) 13(Suppl. 1):S19-23. doi: 10.1089/zeb.2015.1205

97. Sassen RW, Köster R. A molecular toolbox for genetic manipulation of zebrafish. Adv Genom Genet. (2015) 5:151-63. doi: 10.2147/AGG.S57585

98. Zhou W, Boucher RC, Bollig F, Englert C, Hildebrandt F. Characterization of mesonephric development and regeneration using transgenic zebrafish. Am J Physiol Renal Physiol. (2010) 299:F1040-7. doi: 10.1152/ajprenal.00394.2010

99. He B, Ebarasi L, Hultenby K, Tryggvason K, Betsholtz C. Podocingreen fluorescence protein allows visualization and functional analysis of podocytes. J Am Soc Nephrol. (2011) 22:1019-23. doi: 10.1681/ASN.2010121291

100. Seiler C, Pack M. Transgenic labeling of the zebrafish pronephric duct and tubules using a promoter from the enpep gene. Gene Expr Patterns (2011) 11:118-21. doi: 10.1016/j.gep.2010.10.002

101. Noonan HR, Metelo AM, Kamei CN, Peterson RT, Drummond IA, Iliopoulos O. Loss of vhl in the zebrafish pronephros recapitulates early stages of human clear cell renal cell carcinoma. Dis Model Mech. (2016) 9:873-84. doi: 10.1242/dmm.024380

102. Fisher S, Grice EA, Vinton RM, Bessling SL, McCallion AS. Conservation of RET regulatory function from human to zebrafish without sequence similarity. Science (2006) 312:276-9. doi: 10.1126/science.1124070
103. Vasilyev A, Liu Y, Mudumana S, Mangos S, Lam PY, Majumdar A, et al. Collective cell migration drives morphogenesis of the kidney nephron. PLoS Biol. (2009) 7:e9. doi: 10.1371/journal.pbio.1000009

104. Wang Y, Sun ZH, Zhou L, Li Z, Gui JF. Grouper tshbeta promoter-driven transgenic zebrafish marks proximal kidney tubule development. PLoS ONE (2014) 9:e97806. doi: 10.1371/journal.pone.0097806

105. Sanker S, Cirio MC, Vollmer LL, Goldberg ND, McDermott LA, Hukriede NA, et al. Development of high-content assays for kidney progenitor cell expansion in transgenic zebrafish. J Biomol Screen (2013) 18:1193-202. doi: $10.1177 / 1087057113495296$

106. Cianciolo Cosentino C, Skrypnyk NI, Brilli LL, Chiba T, Novitskaya T, Woods C, et al. Histone deacetylase inhibitor enhances recovery after AKI. J Am Soc Nephrol. (2013) 24:943-53. doi: 10.1681/ASN.2012111055

107. Chang MY, Ma TL, Hung CC, Tian YC, Chen YC, Yang CW, et al. Metformin inhibits cyst formation in a zebrafish model of polycystin-2 deficiency. Sci Rep. (2017) 7:7161. doi: 10.1038/s41598-017-07300-x

108. Huang L, Xiao A, Wecker A, McBride DA, Choi SY, Zhou W, et al. A possible zebrafish model of polycystic kidney disease: knockdown of wnt5a causes cysts in zebrafish kidneys. J Vis Exp. (2014) e52156. doi: 10.3791/52156

109. Blum M, De Robertis EM, Wallingford JB, Niehrs C. Morpholinos: antisense and Sensibility. Dev Cell (2015) 35:145-9. doi: 10.1016/j.devcel.2015.09.017

110. Stainier DYR, Raz E, Lawson ND, Ekker SC, Burdine RD, Eisen JS, et al. Guidelines for morpholino use in zebrafish. PLoS Genet. (2017) 13:e1007000. doi: 10.1371/journal.pgen.1007000

111. Eisen JS, Smith JC. Controlling morpholino experiments: don't stop making antisense. Development (2008) 135:1735-43. doi: 10.1242/dev.001115

112. Kok FO, Shin M, Ni CW, Gupta A, Grosse AS, van Impel A, et al. Reverse genetic screening reveals poor correlation between morpholinoinduced and mutant phenotypes in zebrafish. Dev Cell (2015) 32:97-108. doi: 10.1016/j.devcel.2014.11.018

113. Rossi A, Kontarakis Z, Gerri C, Nolte H, Holper S, Kruger M, et al. Genetic compensation induced by deleterious mutations but not gene knockdowns. Nature (2015) 524:230-3. doi: 10.1038/nature14580

114. Cao Y, Semanchik N, Lee SH, Somlo S, Barbano PE, Coifman R, et al. Chemical modifier screen identifies HDAC inhibitors as suppressors of PKD models. Proc Natl Acad Sci USA. (2009) 106:21819-24. doi: 10.1073/pnas.0911987106

115. de Groh ED, Swanhart LM, Cosentino CC, Jackson RL, Dai W, Kitchens CA, et al. Inhibition of histone deacetylase expands the renal progenitor cell population. J Am Soc Nephrol. (2010) 21:794-802. doi: 10.1681/ASN.2009080851

116. Pepperkok R, Ellenberg J. High-throughput fluorescence microscopy for systems biology. Nat Rev Mol Cell Biol. (2006) 7:690-6. doi: 10.1038/nrm1979

117. Mathias JR, Saxena MT, Mumm JS. Advances in zebrafish chemical screening technologies. Future Med Chem. (2012) 4:1811-22. doi: 10.4155/fmc.12.115

118. Yanik MF, Rohde CB, Pardo-Martin C. Technologies for micromanipulating, imaging, and phenotyping small invertebrates and vertebrates. Annu Rev Biomed Eng. (2011) 13:185-217. doi: 10.1146/annurev-bioeng-071910-124703

119. Burns CG, Milan DJ, Grande EJ, Rottbauer W, MacRae CA, Fishman MC. High-throughput assay for small molecules that modulate zebrafish embryonic heart rate. Nat Chem Biol. (2005) 1:263-4. doi: $10.1038 /$ nchembio732

120. Kokel D, Bryan J, Laggner C, White R, Cheung CY, Mateus R, et al. Rapid behavior-based identification of neuroactive small molecules in the zebrafish. Nat Chem Biol. (2010) 6:231-7. doi: 10.1038/nchembio.307

121. Lin S, Zhao Y, Xia T, Meng H, Ji Z, Liu R, et al. High content screening in zebrafish speeds up hazard ranking of transition metal oxide nanoparticles. ACS Nano (2011) 5:7284-95. doi: 10.1021/nn202116p

122. Molina G, Vogt A, Bakan A, Dai W, Queiroz de Oliveira P, Znosko W, et al. Zebrafish chemical screening reveals an inhibitor of Dusp6 that expands cardiac cell lineages. Nat Chem Biol. (2009) 5:680-7. doi: $10.1038 /$ nchembio. 190

123. Pylatiuk C, Sanchez D, Mikut R, Alshut R, Reischl M, Hirth S, et al. Automatic zebrafish heartbeat detection and analysis for zebrafish embryos. Zebrafish (2014) 11:379-83. doi: 10.1089/zeb.2014.1002

124. Zon LI, Peterson RT. In vivo drug discovery in the zebrafish. Nat Rev Drug Discov. (2005) 4:35-44. doi: 10.1038/nrd1606 
125. Wittbrodt JN, Liebel U, Gehrig J. Generation of orientation tools for automated zebrafish screening assays using desktop 3D printing. BMC Biotechnol. (2014) 14:36. doi: 10.1186/1472-6750-14-36

126. Peravali R, Gehrig J, Giselbrecht S, Lutjohann DS, Hadzhiev Y, Muller F, et al. Automated feature detection and imaging for high-resolution screening of zebrafish embryos. Biotechniques (2011) 50:319-24. doi: 10.2144/000113669

127. Pardo-Martin C, Chang TY, Koo BK, Gilleland CL, Wasserman SC, Yanik MF. High-throughput in vivo vertebrate screening. Nat Methods (2010) 7:634-6. doi: 10.1038/nmeth.1481

128. Westhoff JH, Steenbergen PJ, Wagner J, Tönshoff B, Liebel U, Gehrig J. In vivo high content screening in zebrafish to score developmental nephrotoxicity of approved drugs [abstract]. In: 10th European Zebrafish Meeting. Budapest (2017) P-II-157.

129. Pandey G, Westhoff JH, Schaefer F, Gehrig J. An automated high content screening platform to identify cystic kidney disease-modifying substances in zebrafish [abstract]. In: 55th European Renal Association \& European Dialysis and Transplant Association. Copenhagen (2018) SuO018.

130. Pardo-Martin C, Allalou A, Medina J, Eimon PM, Wahlby C, Fatih Yanik M. High-throughput hyperdimensional vertebrate phenotyping. Nat Commun. (2013) 4:1467. doi: 10.1038/ncomms2475

131. Peterson RT, Fishman MC. Designing zebrafish chemical screens. Methods Cell Biol. (2011) 105:525-41. doi: 10.1016/B978-0-12-381320-6.00023-0

132. Conrad C, Wunsche A, Tan TH, Bulkescher J, Sieckmann F, Verissimo F, et al. Micropilot: automation of fluorescence microscopy-based imaging for systems biology. Nat Methods (2011) 8:246-9. doi: 10.1038/nmeth.1558
133. Gunkel M, Eberle JP, Erfle H. Fluorescence-based high-throughput and targeted image acquisition and analysis for phenotypic screening. Methods Mol Biol. (2017) 1563:269-80. doi: 10.1007/978-1-4939-6810-7_17

134. Tischer C, Hilsenstein V, Hanson K, Pepperkok R. Adaptive fluorescence microscopy by online feedback image analysis. Methods Cell Biol. (2014) 123:489-503. doi: 10.1016/B978-0-12-420138-5. 00026-4

135. Mikut R, Dickmeis T, Driever W, Geurts P, Hamprecht FA, Kausler BX, et al. Automated processing of zebrafish imaging data: a survey. Zebrafish (2013) 10:401-21. doi: 10.1089/zeb.2013.0886

Conflict of Interest Statement: GP and JG are employees of DITABIS AG, Pforzheim, Germany.

The remaining author declares that the research was conducted in the absence of any commercial or financial relationships that could be construed as a potential conflict of interest.

Copyright (C) 2018 Gehrig, Pandey and Westhoff. This is an open-access article distributed under the terms of the Creative Commons Attribution License (CC $B Y)$. The use, distribution or reproduction in other forums is permitted, provided the original author(s) and the copyright owner are credited and that the original publication in this journal is cited, in accordance with accepted academic practice. No use, distribution or reproduction is permitted which does not comply with these terms. 